\title{
Chordoma of the corpus callosum: case report
}

\author{
Lorenzo Rinaldo, MD, PhD, ${ }^{1}$ David S. Priemer, MD, ${ }^{2}$ Alexander O. Vortmeyer, MD, PhD, ${ }^{2}$ \\ Aaron A. Cohen-Gadol, MD, MSc, MBA, ${ }^{3}$ Daniel J. Brat, MD, PhD, ${ }^{4}$ Anita Mahajan, ${ }^{5}$ \\ Caterina Giannini, MD, PhD, ${ }^{1,6}$ and Terry C. Burns, MD, PhD ${ }^{1}$
}

\begin{abstract}
Departments of ${ }^{1}$ Neurosurgery, ${ }^{5}$ Radiation Oncology, and ${ }^{6}$ Laboratory Medicine and Pathology, Mayo Clinic, Rochester, Minnesota; '2Department of Anatomic Pathology and Neuropathology, Indiana University School of Medicine, Indianapolis, Indiana; ${ }^{3}$ Goodman Campbell Brain and Spine, Indiana University Department of Neurological Surgery, Indianapolis, Indiana; and ${ }^{4}$ Department of Pathology, Northwestern University Feinberg School of Medicine, Chicago, Illinois
\end{abstract}

\begin{abstract}
Chordomas are neoplasms that typically arise from midline skeletal structures and rarely originate within the intradural compartment of the CNS. A chordoma arising from the corpus callosum has not been previously described. The authors report the surgical management of a chordoma originating within the splenium of the corpus callosum. To determine the incidence and distribution of intracranial intradural chordoma, a literature search for additional cases was performed. MEDLINE was searched using the MeSH keyword "chordoma," yielding 2010 articles. These articles were screened for cases of primary intradural chordoma rostral to the craniocervical junction, which led to the identification of 46 relevant articles. The authors report the case of a 69 -year-old man who initially presented with nonspecific neurological symptoms including spatial disorientation and cognitive decline. These symptoms eventually prompted intracranial imaging, including MRI, which revealed a ring-enhancing, heterogeneous, cystic mass localized within the splenium of the corpus callosum and extending into the bilateral ventricles. The lesion was believed to represent a high-grade glioma and the patient underwent a left interhemispheric approach and subtotal resection. After pathologic evaluation confirmed a diagnosis of an anaplastic chordoma, the patient underwent further resection. A gross-total resection (GTR) was achieved with a transfalcine approach to the contralateral portion of the tumor. Postoperatively, the patient had a partial left homonymous quadrantanopsia, but was otherwise at his neurological baseline. Proton beam radiotherapy was performed to the resection cavity but diffuse intraventricular disease ensued. The results of a literature search suggest that a chordoma arising in the corpus callosum has not been previously described. The present case demonstrates that chordomas can occur in the corpus callosum, and illustrates the utility of a transfalcine approach for GTR of lesions in this location, as well as the need for improved strategies to prevent intraventricular dissemination.
\end{abstract}

https://thejns.org/doi/abs/10.3171/2018.6.JNS181028

KEYWORDS brain neoplasms; chordoma; corpus callosum; oncology

$\mathrm{C}$ HORDOMAS are rare neoplasms originating from notochordal remnants that typically occur along the axial skeleton. ${ }^{26}$ Rostral to the craniocervical junction, chordomas are most commonly found within the bone of midline skull base structures ${ }^{42}$ although exclusively intradural chordomas have been previously reported. ${ }^{1}$ In this paper we report an exceptionally rare case of a primary chordoma originating in the splenium of the corpus callosum. To the best of our knowledge, a chordoma in this location has not been previously described. Albeit extremely rare, this case demonstrates the previously unappreciated capacity for these neoplasms to occur intraaxially within the supratentorial compartment of the CNS.

\section{Literature Search}

To investigate for previous reports of an intracranial chordoma occurring in the corpus callosum, we searched MEDLINE using the MeSH keywords "chordoma" and "corpus callosum." This search yielded no results. We then searched MEDLINE using only the keyword "chordoma." While applying article-type filters selecting for 
case reports, clinical studies, clinical trials, comparative studies, observational studies, reviews, and systematic reviews, this search yielded a total of 2010 articles. Articles referencing primary extradural chordomas or spinal chordomas located caudal to the craniocervical junction were excluded on the basis of title alone. Articles potentially meeting criteria for inclusion on the basis of title and abstract were reviewed and reports of pathologically confirmed chordomas arising within the intradural space rostral to the craniocervical junction were included, yielding a total of 47 articles.

\section{Case Report}

\section{History and Examination}

We report the case of a 69-year-old man without a significant medical history who initially presented with symptoms of spatial disorientation manifesting as difficulty finding his way to work while driving and inability to find previously familiar locations at his workplace. He also noted difficulty with semantic memory and simple arithmetic, as well as occasional odd sensations at the top of his lip, wherein he would reexperience the sensation of light touch shortly after the initial stimulation. After approximately 6 months of progressive cognitive decline, he presented for medical evaluation. On neurological examination the patient did not have any focal deficits. A head CT scan was obtained and revealed a predominantly right-sided, hypointense mass centered within the splenium of the corpus callosum and protruding into bilateral ventricular atria (Fig. 1A). Follow-up MRI demonstrated a rim-enhancing, cystic-appearing mass that was intimately associated with bilateral internal cerebral veins and the vein of Galen (Fig. 1B and C).

\section{Operation}

The radiological appearance of the lesion was suggestive of glioblastoma, and thus the patient consented to surgery to obtain diagnostic tissue and tumor debulking. A left parietal craniotomy and interhemispheric approach to the lesion was performed. Intraoperative pathology was supportive of the putative diagnosis and thus no attempt was made to obtain a gross-total resection (GTR) of the presumed infiltrative lesion. Postoperatively, the patient awoke with no new neurological deficits. Postoperative imaging demonstrated residual tumor bilaterally, with a predominant focus of tumor in the right splenium. Permanent pathology was believed to be inconsistent with glioblastoma; the presence of physaliferous cells prompted staining for brachyury, a lineage-specific marker of chordoma, which was found to be positive. Independent neuropathological evaluation at multiple institutions confirmed the diagnosis of anaplastic chordoma.

A complete MRI of the spine showed no evidence of disease along the spinal axis. Given the strong and well-
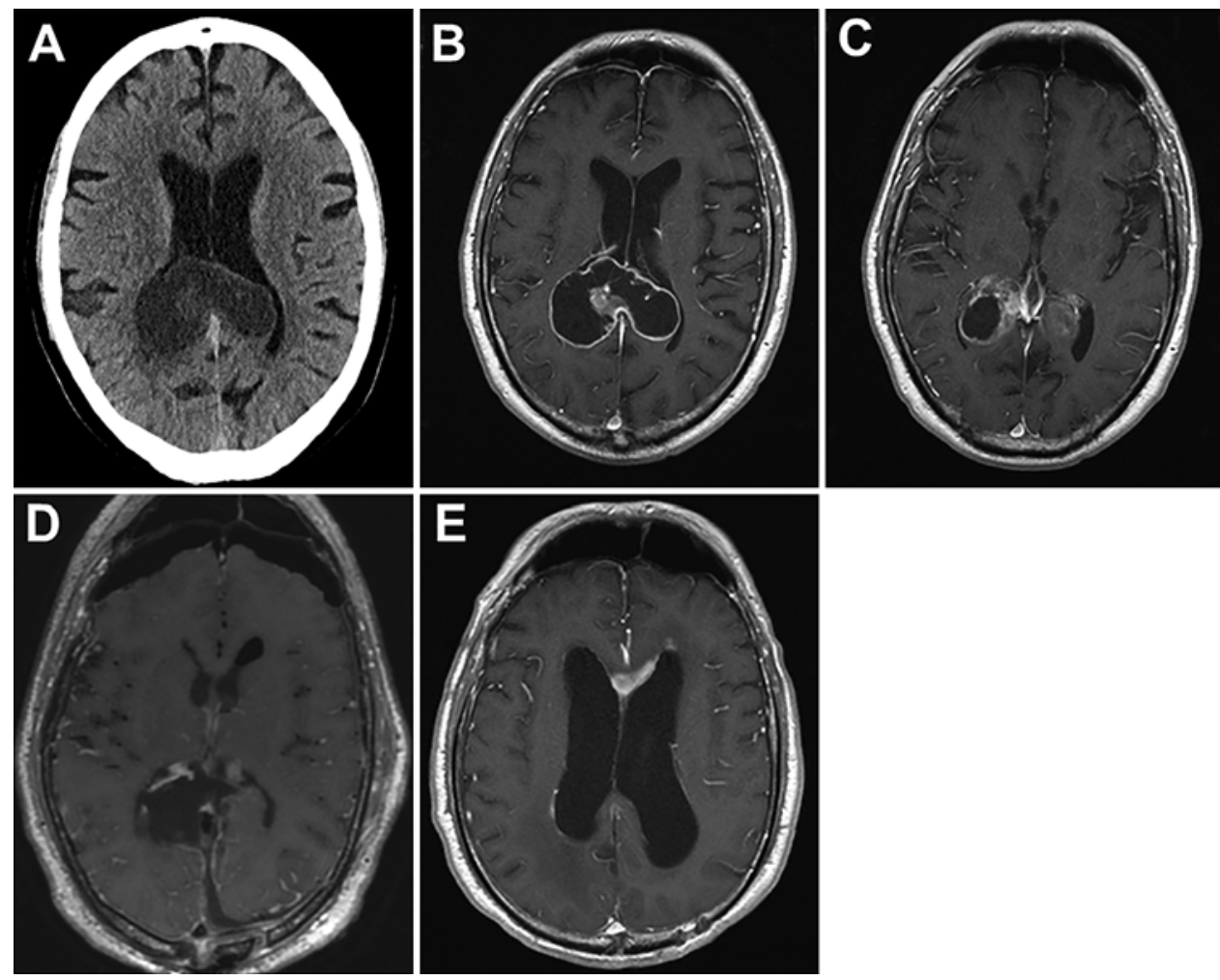

FIG. 1. Axial pre- and postoperative imaging. A: Head CT reveals a hypodense mass localized within the splenium of the corpus callosum. B and C: MRI of the brain demonstrates a predominantly ring-enhancing mass in close proximity to the deep veins of this region. D: Postoperative imaging after the second resection obtained in the intraoperative MRI suite demonstrates a GTR of the previously observed enhancing lesion. E: A follow-up MR image demonstrated multifocal periventricular enhancing lesions, the largest of which was located in the anterior corpus callosum, with associated ventriculomegaly. 


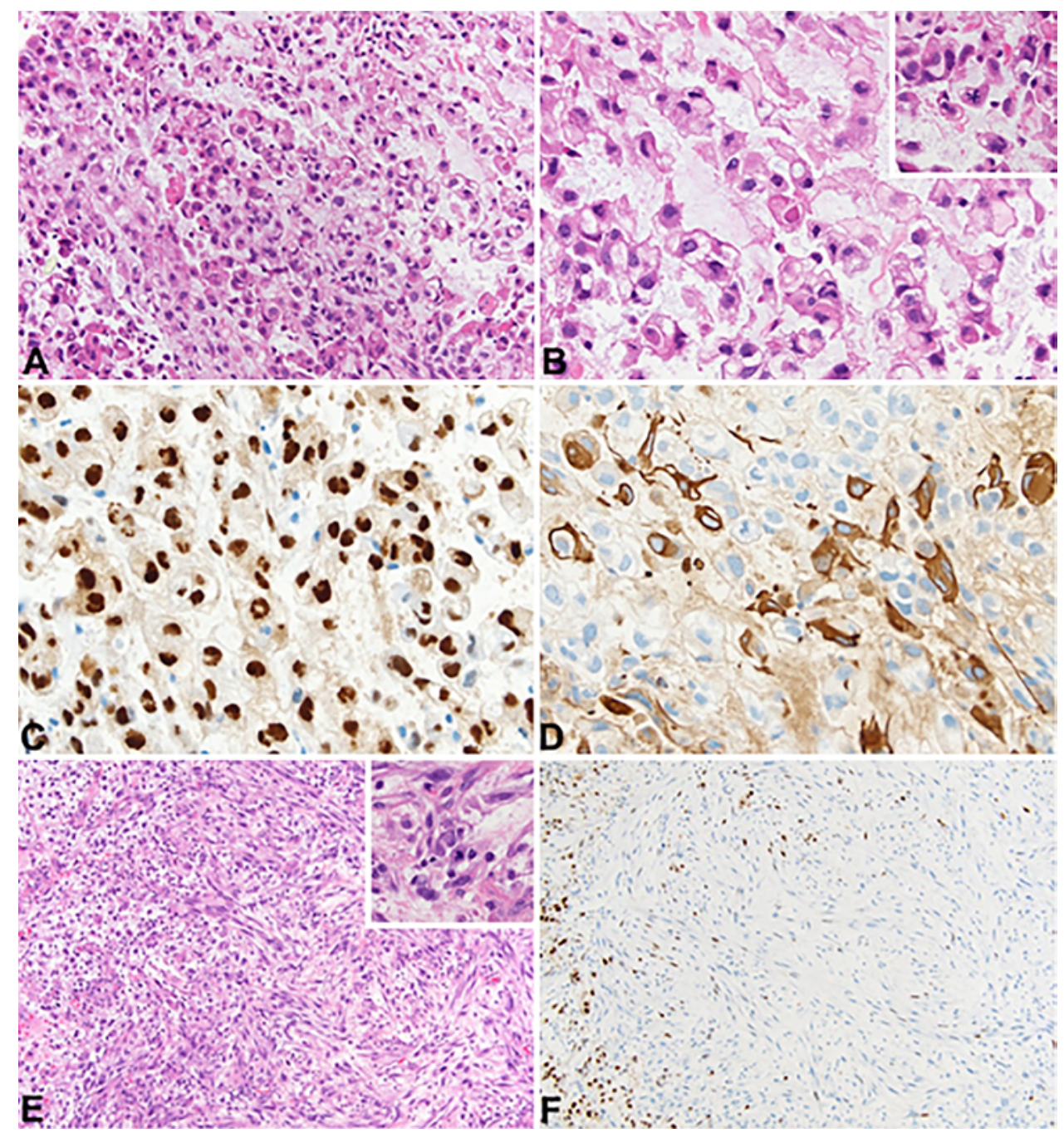

FIG. 2. Photomicrographs of pathological specimens. A and B: The first biopsy showed a tumor composed of cells with clear to eosinophilic cytoplasm arranged in small cords embedded in abundant background myxoid matrix. Scattered atypical mitotic figures were present $(B$, inset). $\mathrm{H}$ \& E. Original magnification $\times 100(A)$ and $\times 400$ (B and inset). $C$ and $D$ : Tumor cells were positive for brachyury, a marker highly specific for chordoma (C), and expressed glial fibrillary acidic protein focally, a finding that has been previously reported in chordoma (D). Original magnification $\times 400$. E: In the second biopsy procedure, in addition to the classic chordoma component, nodules composed of undifferentiated spindle cells with mitotic activity (inset) were present, supporting the diagnosis of dedifferentiated chordoma. H \& E. Original magnification $\times 100$ and $\times 400$ (inset). F: Brachyury was not expressed in the dedifferentiated component of the tumor. Original magnification $\times 100$. Figure is available in color online only.

established association between complete resection and improved prognosis, ${ }^{22,26,56,61,65}$ the patient was recommended to undergo a second surgery to obtain GTR. Surgery was performed in the intraoperative MRI suite with the patient positioned prone. The lesion was initially approached through the previous left-sided craniotomy. A dissection plane was maintained in the white matter surrounding the relatively gray, translucent lesion. Specimens were taken for frozen sectioning and found to be consistent with chordoma. After amputating and removing the dissected left-sided portion of the tumor, a generous transfalcine window was created to the larger right side of the residual tumor. This was similarly circumferentially dissected, including all adjacent ependyma. After dissecting from the midline venous structures, the lesion was internally debulked to facilitate delivery of the remaining tumor through the falcine window. Postoperative MRI demonstrated GTR of the lesion with preservation of midline venous structures (Fig. 1D). The patient awoke with a partial homonymous left lower quadrantanopsia, but was otherwise at his preoperative neurological baseline. The patient was discharged on postoperative day 2 .

\section{Pathological Findings}

Histopathological and immunohistochemical staining of specimens confirmed the diagnosis of chordoma and revealed diffuse positivity for brachyury (Fig. 2A-D). Areas containing undifferentiated spindle cells with high mitotic activity were also visualized (Fig. 2E), consistent with a dedifferentiated chordoma. Brachyury expression 
TABLE 1. Reported spatial distribution of primary intradural chordomas

\begin{tabular}{lccl}
\hline \multicolumn{1}{c}{ Location } & Intra- vs Extraaxial & No. of Occurrences & Citations \\
\hline Prepontine cistern & Extra & 30 & $1,4,5,11-13,15,21,27,28,33,37,39,40,46,50,52,53,55,58,59,62$ \\
\hline Intra- \& suprasellar space & Extra & 19 & $16,19,29-31,34,41,45,50,51,54,57,63,66,68$ \\
\hline Meckel's cave & Extra & 2 & 3,38 \\
\hline Anterior cranial fossa & Extra & 1 & 7 \\
\hline Cerebellar hemisphere & Intra & 1 & 17 \\
\hline Cerebellopontine angle & Extra & 1 & 35 \\
\hline Foramen magnum & Extra & 1 & 32 \\
\hline Pineal region & Extra & 1 & 23 \\
\hline Posterior fossa & Extra & 1 & 2 \\
\hline Sphenoid wing & Extra & 1 & 36 \\
\hline Tentorium cerebelli & Extra & 1 & 64 \\
\hline 3rd ventricle & Extra & 1 & 14 \\
\hline
\end{tabular}

was absent in the dedifferentiated component of the tumor (Fig. 2F).

\section{Postoperative Course}

The patient was subsequently treated with fractionated proton beam radiotherapy, receiving a total dose of 70 Gy over 35 treatments to the tumor bed with weekly radiological monitoring of the postoperative changes and normal structures. The patient's posttreatment course was complicated by a lower-extremity deep venous thrombosis requiring anticoagulation. While receiving anticoagulation therapy the patient developed a chronic right subdural hematoma that required burr-hole drainage. The collection recurred after drainage, but the patient remained minimally symptomatic and thus was managed with observation, with subsequent spontaneous resolution. Approximately 8 months after his initial surgery, the patient experienced an abrupt functional decline. Repeat MRI demonstrated numerous foci of periventricular enhancement as well as ventriculomegaly, concerning for disseminated disease (Fig. 1E). Spinal imaging remained negative. Radiation was performed to the areas of recurrence, although his poor functional status ultimately led family to pursue palliative care.

\section{Literature Review Results}

We performed a review of the available literature to discern the spatial distribution of chordomas occurring intradurally within the intracranial space. Our search yielded 47 articles representing 61 cases of primary intradural chordoma. A majority of these reports (30 cases) described chordomas originating within the prepontine space ventral to the brainstem, consistent with the clival origin of

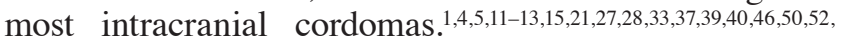
53,55,58,59,62 The second most frequent location was the intra- and suprasellar space (19 cases), ${ }^{16,19,29-31,34,41,45,50,51,54,57}$, 63,66,68 with 1 report describing a chordoma arising from the hypothalamus with extension into the third ventricle. ${ }^{14}$ Apart from the present case, the only instance of an intraaxial chordoma was reported by Dow and colleagues, who described a chordoma arising within the cerebellar paren- chyma in a pediatric patient. ${ }^{17}$ The remaining reports described dural-based lesions at various locations within the intracranial compartment, including the anterior cranial fossa, ${ }^{7}$ cerebellopontine angle, ${ }^{35}$ foramen magnum, ${ }^{32}$ tentorium cerebelli, ${ }^{64}$ Meckel's cave, ${ }^{3,38}$ pineal region, ${ }^{23}$ posterior fossa, ${ }^{2}$ and along the sphenoid wing..$^{36}$ The reported spatial distribution of intracranial intradural chordomas is summarized in Table 1.

\section{Discussion}

In this paper we report a case of a pathologically confirmed chordoma occurring within the splenium of the corpus callosum. To our knowledge, a chordoma in this location has not been previously reported.

Chordomas are believed to arise from vestiges of notochordal tissue. ${ }^{26}$ Prior to involution initiating at approximately the sixth or seventh week of embryonic life, the notochord extends from the most caudal end of the vertebral column and terminates in what will develop into the dorsum sellae of the skull base. ${ }^{26}$ As such, the finding of a chordoma within the corpus callosum is particularly surprising. While within the first few years of postnatal life the notochord persists only as the nucleus pulposus of intervertebral discs, chordomas, which have never been observed to originate within intervertebral discs, are thought to arise from rests of notochordal cells located at various points along the central skeletal axis. ${ }^{26}$ Cadaveric and radiographic studies have documented these entities incidentally, most frequently in the prepontine extradural space posterior to the clivus, ${ }^{43,48,67}$ which is consistent with the observed spatial distribution of clinically evident chordomas. ${ }^{42}$ Whether or not these notochordal vestiges may also be rarely identifiable within the corpus callosum requires further investigation.

Lesions within the splenium of the corpus callosum have traditionally been approached via a posterior interhemispheric route. ${ }^{18}$ In the present case, this approach was supplemented with a transfalcine corridor to the rightsided aspect of the lesion, facilitating a GTR without the need for an additional right-sided craniotomy. Outcomes of this approach have been described primarily for lesions within the atrium of the lateral ventricle, with specific 
advantages including avoidance of the optic radiations and more favorable working angles when compared to an ipsilateral approach, ${ }^{6,8}$ both of which were applicable to this case. Surgical outcomes of transfalcine approaches to lesions within the splenium of the corpus callosum require further investigation. Alternative approaches would have included a more anterior interhemispheric trajectory; however, the likely need to retract bilateral motor cortices, longer distance to the lesion, and risk of injury to the anterior corpus callosum made this a less favorable option.

Postsurgical management in this case posed challenges due to lack of available data. Although the importance of complete resection of chordomas for hope of long-term survival is well established, the pattern of likely recurrence after GTR for an intradural chordoma is unknown. Moreover, final pathology was consistent with a dedifferentiated chordoma, for which prognosis, particularly in intradural locations, is less well-defined. However, available evidence suggests this subtype portends a more aggressive clinical course than standard chordomas. ${ }^{24,44,60}$ We elected to pursue proton beam radiotherapy, based on robust data for clival and sacral resections that adjuvant radiotherapy to the resection cavity improves long-term survival, even after GTR. ${ }^{25,26}$ The use of protons as opposed to traditional radiotherapy also minimized radiation exposure to surrounding midline structures, allowing delivery of a higher dosage (70 Gy) to the tumor bed..$^{20}$ Compared to stereotactic radiosurgery, which is also used with success for chordomas, ${ }^{10}$ proton beam radiotherapy in this case permitted a larger treatment field that included the adjacent ventricular surfaces. Unfortunately, the patient nevertheless experienced multifocal periventricular recurrence less than 1 year after GTR. Chordomas with intradural extension are at risk of seeding along subarachnoid spaces; ${ }^{26}$ the proximity of the patient's primary lesion to the ventricular system, and the intraventricular exposure during resection, likely elevated his risk of recurrence. Neoadjuvant radiation has been proposed to reduce the risk of leptomeningeal spread for metastatic brain tumors. ${ }^{47} \mathrm{Had}$ the diagnosis been known ahead of time, whether or not preoperative radiation could have reduced the risk of dissemination is unknown. Given prone positioning at the time of surgery, consideration was given to radiating the anterior ventricular system in addition to the resection cavity to attenuate risk of microscopic disease. However, the risk of morbidity from treating the entire ventricular system was believed to exceed potential benefits. Finally, the patient was noted to have communicating hydrocephalus at the time of tumor recurrence. Although data specific to hydrocephalus secondary to disseminated chordoma is lacking, permanent CSF diversion has been shown to be effective in improving symptoms related to hydrocephalus in patients with high-grade gliomas, ${ }^{9,49}$ although radiological evidence of intraventricular extension is a poor prognostic sign. ${ }^{49}$ Abdominal seeding following a ventriculoperitoneal shunt placement for hydrocephalus in the setting of an intradural chordoma has been reported,,$^{23}$ and thus was not pursued in this case.

The present report describes a chordoma arising within the splenium of the corpus callosum, a novel site of origin for this rare neoplasm. This case highlights the capacity for these lesions to occur in extraosseous and intraaxial locations within the CNS, the pathophysiology of which requires further investigation.

\section{References}

1. AlOtaibi F, Guiot MC, Muanza T, Di Maio S: Giant petroclival primary intradural chordoma: case report and systematic review of the literature. J Neurol Surg Rep 75:e160e169, 2014

2. Anderson S, Sato Y, Kirby P, Buatti JM, Menezes A: Disseminated subarachnoid chordoma: long-term favorable follow-up of a pediatric patient. Pediatr Radiol 42:878-880, 2012

3. Barresi V, Caffo M, Alafaci C, Granata F, Tuccari G: Intradural chordoma of the Meckel's cave: a challenging differential diagnosis. Neuropathology 32:577-582, 2012

4. Bergmann M, Abdalla Y, Neubauer U, Schildhaus HU, Probst-Cousin S: Primary intradural chordoma: report on three cases and review of the literature. Clin Neuropathol 29:169-176, 2010

5. Bhat DI, Yasha M, Rojin A, Sampath S, Shankar SK: Intradural clival chordoma: a rare pathological entity. J Neurooncol 96:287-290, 2010

6. Bohnstedt BN, Kulwin CG, Shah MV, Cohen-Gadol AA: Posterior interhemispheric transfalcine transprecuneus approach for microsurgical resection of periatrial lesions: indications, technique, and outcomes. J Neurosurg 123:10451054,2015

7. Bulters DO, Webb A, Shenouda E: Chordoma of the anterior skull base presenting as a swelling of the medial canthus of the eye. Br J Oral Maxillofac Surg 48:211-213, 2010

8. Burkhardt JK, Winkler EA, Lawton MT: Contralateral posterior interhemispheric approach to deep medial parietooccipital vascular malformations: surgical technique and results. J Neurosurg 129:198-204, 2018

9. Castro BA, Imber BS, Chen R, McDermott MW, Aghi MK: Ventriculoperitoneal shunting for glioblastoma: risk factors, indications, and efficacy. Neurosurgery 80:421-430, 2017

10. Chang SD, Martin DP, Lee E, Adler JR Jr: Stereotactic radiosurgery and hypofractionated stereotactic radiotherapy for residual or recurrent cranial base and cervical chordomas. Neurosurg Focus 10(3):E5, 2001

11. Chang SW, Gore PA, Nakaji P, Rekate HL: Juvenile intradural chordoma: case report. Neurosurgery 62:E525-E527, 2008

12. Choo YS, Joo SW, Noh SJ, Lee SI: Intradural retroclival chordoma. J Korean Neurosurg Soc 46:152-155, 2009

13. Ciarpaglini R, Pasquini E, Mazzatenta D, Ambrosini-Spaltro A, Sciarretta V, Frank G: Intradural clival chordoma and ecchordosis physaliphora: a challenging differential diagnosis: case report. Neurosurgery 64:E387-E388, 2009

14. Commins D, Baran GA, Molleston M, Vollmer D: Hypothalamic chordoma. Case report. J Neurosurg 81:130-132, 1994

15. Danilewicz B, Danilewicz M, Czepko R, Stachura K: [Intradural clivus chordoma: surgical treatment with no tumor regrowth 12 years after surgery.] Przegl Lek 57:178-180, 2000 (Polish)

16. de Cremoux P, Turpin G, Hamon P, de Gennes JL: [Intrasellar chordoma (author's transl).] Sem Hop 56:1769-1773, $1980(\mathrm{Fr})$

17. Dow GR, Robson DK, Jaspan T, Punt JA: Intradural cerebellar chordoma in a child: a case report and review of the literature. Childs Nerv Syst 19:188-191, 2003

18. Duffau H, Khalil I, Gatignol P, Denvil D, Capelle L: Surgical removal of corpus callosum infiltrated by low-grade glioma: functional outcome and oncological considerations. J Neurosurg 100:431-437, 2004 
19. Elias Z, Powers SK: Intrasellar chordoma and hyperprolactinemia. Surg Neurol 23:173-176, 1985

20. Estabrook NC, McDonald MW, Hoene TA, Bartlett GK, Johnstone PA, McMullen KP, et al: Proton radiotherapy for midline central nervous system lesions: a class solution. Oncology 89:111-117, 2015

21. Feng K, Qiuhang Z, Qiuyi Q: Transclival cerebrospinal fluid rhinorrhea as the initial presenting symptom of a tiny intradural chordoma. J Clin Neurosci 17:1083-1085, 2010

22. Fernandez-Miranda JC, Gardner PA, Snyderman CH, Devaney KO, Mendenhall WM, Suárez C, et al: Clival chordomas: a pathological, surgical, and radiotherapeutic review. Head Neck 36:892-906, 2014

23. Figueiredo EG, Tavares WM, Welling L, Rosemberg S, Teixeira MJ: Ectopic pineal chordoma. Surg Neurol Int 2:145, 2011

24. Forsyth PA, Cascino TL, Shaw EG, Scheithauer BW, O'Fallon JR, Dozier JC, et al: Intracranial chordomas: a clinicopathological and prognostic study of 51 cases. J Neurosurg 78:741-747, 1993

25. George B, Bresson D, Bouazza S, Froelich S, Mandonnet E, Hamdi S, et al: [Chordoma.] Neurochirurgie 60:63-140, 2014 (Fr)

26. George B, Bresson D, Herman P, Froelich S: Chordomas: a review. Neurosurg Clin N Am 26:437-452, 2015

27. Gonzalez-Martinez JA, Guthikonda M, Vellutini E, Zamorano L, Li Q, Kupski W, et al: Intradural invasion of chordoma: two case reports. Skull Base 12:155-161, 2002

28. Ito E, Saito K, Nagatani T, Ishiyama J, Terada K, Yoshida M, et al: Intradural cranial chordoma. World Neurosurg 73:194-197, e31, 2010

29. Jiagang L, Yanhui L, Xueying S, Qing M: Intradural suprasellar chondroid chordoma. J Clin Neurosci 17:402-403, 2010

30. Kagawa T, Takamura M, Moritake K, Tsutsumi A, Yamasaki $\mathrm{T}$ : A case of sellar chordoma mimicking a non-functioning pituitary adenoma with survival of more than 10 years. Noshuyo Byori 10:103-106, 1993

31. Kakuno Y, Yamada T, Hirano H, Mori H, Narabayashi I: Chordoma in the sella turcica. Neurol Med Chir (Tokyo) 42:305-308, 2002

32. Katayama Y, Tsubokawa T, Hirasawa T, Takahata T, Nemoto $\mathrm{N}$ : Intradural extraosseous chordoma in the foramen magnum region. Case report. J Neurosurg 75:976-979, 1991

33. Kawanabe Y, Ueda S, Sasaki N, Hoshimaru M: Simultaneous discovery of cranial and spinal intradural chordomas: case report. Neurol Med Chir (Tokyo) 54:930-935, 2014

34. Kim SK, Kim YH, Park CK, Kim MA, Park SH: Intracranial intradural chordoma presenting with intraventricular hemorrhage. Clin Neurol Neurosurg 114:1189-1192, 2012

35. Korinth M, Schönrock L, Mayfrank L, Gilsbach JM: Primary intradural pontocerebellar chordoma metastasizing in the subarachnoid spinal canal. Zentralbl Neurochir 60:146150,1999

36. Kunert P, Dziedzic T, Matyja E, Marchel A: Intradural chordoma mimicking a lateral sphenoid wing meningioma: a case report. Folia Neuropathol 50:407-412, 2012

37. Li DR, Ishikawa T, Zhao D, Michiue T, Quan L, Zhu BL, et al: Unexpected sudden death due to intracranial chordoma: an autopsy case. Forensic Sci Int 200:e15-e18, 2010

38. Lu CY, Chai CY, Chiang IC: Chordoma mimicking the trigeminal schwannoma: a case report. Clin Imaging 28:187190, 2004

39. Mapstone TB, Kaufman B, Ratcheson RA: Intradural chordoma without bone involvement: nuclear magnetic resonance (NMR) appearance. Case report. J Neurosurg 59:535-537, 1983

40. Masui K, Kawai S, Yonezawa T, Fujimoto K, Nishi N: Intradural retroclival chordoma without bone involvement-case report. Neurol Med Chir (Tokyo) 46:552-555, 2006
41. Mathews W, Wilson CB: Ectopic intrasellar chordoma. Case report. J Neurosurg 40:260-263, 1974

42. McMaster ML, Goldstein AM, Bromley CM, Ishibe N, Parry DM: Chordoma: incidence and survival patterns in the United States, 1973-1995. Cancer Causes Control 12:1-11, 2001

43. Mehnert F, Beschorner R, Küker W, Hahn U, Nägele T: Retroclival ecchordosis physaliphora: MR imaging and review of the literature. AJNR Am J Neuroradiol 25:1851-1855, 2004

44. Naka T, Boltze C, Kuester D, Schulz TO, Schneider-Stock R, Kellner A, et al: Alterations of G1-S checkpoint in chordoma: the prognostic impact of p53 overexpression. Cancer 104:1255-1263, 2005

45. Navas M, Martinez P, Shakur SF, Barbosa A, Barcena E, Gordillo C, et al: Intrasellar chordoma associated with a primitive persistent trigeminal artery. Turk Neurosurg 25:146-153, 2015

46. Nishigaya K, Kaneko M, Ohashi Y, Nukui H: Intradural retroclival chordoma without bone involvement: no tumor regrowth 5 years after operation. Case report. J Neurosurg 88:764-768, 1998

47. Patel KR, Burri SH, Asher AL, Crocker IR, Fraser RW, Zhang $\mathrm{C}$, et al: Comparing preoperative with postoperative stereotactic radiosurgery for resectable brain metastases: a multi-institutional analysis. Neurosurgery 79:279-285, 2016

48. Ribbert H, Steiner H: Uber die Ecchondrosis physaliphora sphenooccipitalis. Zentralbl Allg Pathol Anat 5:457-461, 1894

49. Rinaldo L, Brown D, Lanzino G, Parney IF: Outcomes following cerebrospinal fluid shunting in high-grade glioma patients. J Neurosurg 129:984-996, 2018

50. Roberti F, Sekhar LN, Jones RV, Wright DC: Intradural cranial chordoma: a rare presentation of an uncommon tumor. Surgical experience and review of the literature. J Neurosurg 106:270-274, 2007

51. Shinmura F, Ooiwa Y, Sakata R, Ariwa R, Sakakibara T: [Intracranial chordoma-report of two cases with cytochemical study.] No Shinkei Geka 13:563-568, 1985 (Jpn)

52. Takahashi H, Kinoshita Y, Usui S, Arihiro K, Kimura S, Mitsuhara T, et al: [A case of intradural retroclival chordoma.] No Shinkei Geka 45:623-627, 2017 (Jpn)

53. Tashiro T, Fukuda T, Inoue Y, Nemoto Y, Shakudo M, Katsuyama J, et al: Intradural chordoma: case report and review of the literature. Neuroradiology 36:313-315, 1994

54. Thodou E, Kontogeorgos G, Scheithauer BW, Lekka I, Tzanis $\mathrm{S}$, Mariatos $\mathrm{P}$, et al: Intrasellar chordomas mimicking pituitary adenoma. J Neurosurg 92:976-982, 2000

55. Uda T, Ohata K, Takami T, Hara M: An intradural skull base chordoma presenting with acute intratumoral hemorrhage. Neurol India 54:306-307, 2006

56. Van Gompel JJ, Janus JR: Chordoma and chondrosarcoma. Otolaryngol Clin North Am 48:501-514, 2015

57. Vaquero J, Martinez R, Rossi E, Bravo G: Chordoma. Neurosurgery 13:737-738, 1983

58. Vellutini E de A, de Oliveira MF: Intradural chordoma presenting with intratumoral bleeding. J Clin Neurosci 25:139142,2016

59. Vinke RS, Lamers EC, Kusters B, van Lindert EJ: Intradural prepontine chordoma in an 11-year-old boy. A case report. Childs Nerv Syst 32:169-173, 2016

60. von Witzleben A, Goerttler LT, Lennerz J, Weissinger S, Kornmann M, Mayer-Steinacker R, et al: In chordoma, metastasis, recurrences, Ki-67 index, and a matrix-poor phenotype are associated with patients' shorter overall survival. Eur Spine J 25:4016-4024, 2016

61. Walcott BP, Nahed BV, Mohyeldin A, Coumans JV, Kahle KT, Ferreira MJ: Chordoma: current concepts, management, and future directions. Lancet Oncol 13:e69-e76, 2012

62. Wang L, Wu Z, Tian K, Li G, Zhang J: Clinical and patho- 
logical features of intradural retroclival chordoma. World Neurosurg 82:791-798, 2014

63. Wanibuchi M, Uede T, Ishiguro M, Tatewaki K, Kurokawa Y, Yoshida Y: [A case of suprasellar intradural chordoma.] No Shinkei Geka 22:269-272, 1994 (Jpn)

64. Warnick RE, Raisanen J, Kaczmar T Jr, Davis RL, Prados MD: Intradural chordoma of the tentorium cerebelli. Case report. J Neurosurg 74:508-511, 1991

65. Williams BJ, Raper DM, Godbout E, Bourne TD, Prevedello DM, Kassam AB, et al: Diagnosis and treatment of chordoma. J Natl Compr Canc Netw 11:726-731, 2013

66. Wolfe JT III, Scheithauer BW: "Intradural chordoma" or "giant ecchordosis physaliphora"? Report of two cases. Clin Neuropathol 6:98-103, 1987

67. Wyatt RB, Schochet SS Jr, McCormick WF: Ecchordosis physaliphora. An electron microscopic study. J Neurosurg 34:672-677, 1971

68. Zeng HH, Yu XB, Fan LF, Chen G: Diagnostic clues and treatment of intradural cranial chordoma. Chin Med J (Engl) 129:2895-2896, 2016

\section{Disclosures}

The authors report no conflict of interest concerning the materials or methods used in this study or the findings specified in this paper.

\section{Author Contributions}

Conception and design: Burns, Rinaldo, Vortmeyer, Giannini. Acquisition of data: Rinaldo. Analysis and interpretation of data: all authors. Drafting the article: Rinaldo. Critically revising the article: all authors. Reviewed submitted version of manuscript: all authors. Approved the final version of the manuscript on behalf of all authors: Burns. Study supervision: Burns.

\section{Correspondence}

Terry C. Burns: Mayo Clinic, Rochester, MN. burns.terry@ mayo.edu. 